Гневашева Вера Анатольевна

доктор экономических наук, профессор Московского государственного института международных отношений - Университета МИД РФ

\section{ЦЕННОСТНЫЕ ПРЕДПОСЫЛКИ ПРОФЕССИОНАЛЬНОЙ МОТИВАЦИИ СТУДЕНЧЕСКОЙ МОЛОДЕЖИ РОССИИ: ГЕНДЕРНЫЙ АСПЕКТ}

\begin{abstract}
Аннотация:
Статья посвящена проблемам ценностного становления современной студенческой молодежи России и формирования профессиональной мотивации и профессиональной ориентации будущих специалистов на этапе формирования рабочей силы. Обозначено, что профессиональная мотивация является важным фактором структурного формирования рабочей силы. Раскрываются особенности складывания отношения к высшему образованию у студентов в зависимости от их гендерной принадлежности. Выявлены идентичные области социального восприятия и позиции, позволяющие говорить о существующих различиях. Отмечено, что ценностные ориентации молодежи точнее выявляются по косвенным показателям опросов. В заключение сделан вывод о возможности оценки студенческой молодежи по принципу внутреннего единства группы. Статья подготовлена на основе результатов авторских эмпирических исследований за период 2004-2018 ге.
\end{abstract}

Ключевые слова:

формирование рабочей силы, вуз, ценностные ориентиры, социальные ориентиры, профессиональные ориентиры, профессиональная мотивация, гендер, студенческая молодежь, исследования.

\section{Gnevasheva Vera Anatolyevna}

D.Phil. in Economics, Professor, Moscow State Institute of International Relations (University) of the Ministry of Foreign Affairs of the Russian Federation

\section{VALUE-BASED BACKGROUNDS TO CAREER MOTIVATION OF RUSSIAN STUDENTS: A GENDER PERSPECTIVE}

\section{Summary:}

The paper deals with fostering values, career motivation, and vocational guidelines among contemporary Russian students when developing a labor force. Career motivation is regarded as a pivotal factor in the structural development of human resources. The study discusses the attitudes of students differentiated by gender towards higher education. The research reveals the similarities and differences in social perception of respondents. Students' values can be precisely identified through the proxy indicators. Besides, it is possible to assess students according to the principal of the internal cohesion of the group. The research is based on empirical data obtained by the author for 2004-2018.

Keywords: labor force development, university, values, social guidelines, vocational guidelines, career motivation, gender, students, research.

По мере социально-экономической трансформации российского общества у населения появляются интерес к профессиональному образованию и стремление сформировать профессиональные компетенции согласно существующим представлениям о востребованности специальностей, общественным и собственным ожиданиям. В силу несовпадения во времени процессов формирования спроса на программы высшего образования и предложения на рынке труда проблема структурной безработицы становится еще острее. Преимущественно это относится к молодежи с высшим образованием, возникает перепроизводство специалистов. Важность оценки общественного выбора вуза, понимание многокритериальности этого выбора являются значимыми для выработки программ оптимизации распределения образовательных ресурсов и построения структуры распределения направлений подготовки в соответствии с требованиями рынка труда и ожиданиями абитуриентов.

Учеными и исследователями неизменно отмечается важность ценностного становления молодежи с точки зрения необходимости формирования потенциала общества, значимого для всех сфер хозяйственной жизнедеятельности, в том числе и рынка труда.

В статье профрессора А. Лидаки отмечается, что сегодняшняя молодежь - это завтрашние активные представители общества, высококвалифицированные специалисты. При этом важно помнить, что в основном образованные и творческие люди обеспечивают устойчивое социальноэкономическое развитие [1, р. 399].

В период реформ 1990-х гг. в молодежной среде резко снизилось значение интегральных ценностей, являвшихся ориентирами в советское время. В то же время базовые ценности передаются из поколения в поколение в достаточно устойчивых конфигурациях [2]. В исследованиях ценностных ориентаций молодежи важны те косвенные обстоятельства, которые отмечаются в прожективных вопросах. Ответы на косвенные вопросы о ценностных ориентациях молодежи в конечном итоге точнее показывают действительные предпочтения молодых людей, чем прямые вопросы о ценностях. 
Для молодежи характерно становление ценностно-нормативной системы, что означает действие иных механизмов, нежели в ситуации переоценки ценностей. В этом случае применяемые в российской социологии сопоставления ценностных шкал разных возрастных групп (включая молодежь) дают информацию о разнообразии ценностей, разделяемых в российском обществе, но не вполне адекватно фиксируют ценностный мир и стратегические предпочтения молодежи как таковой.

Гендерные аспекты являются зачастую определяющими в формировании ряда социальных тенденций, детерминирующих последующие экономические преобразования. Вместе с тем следует учитывать современные условия сглаживания гендерных различий в социальном плане при построении комплексных подходов социально-экономического развития.

Так, ряд ученых отмечает, что конец XX в. определяет гендерный вопрос в качестве одного из значимых, актуальных для развития общества и человечества в целом. Гендерные различия влияют на общественные изменения в условиях глобализации экономики. Усложнение социальных связей есть неразрывное взаимодействие и с гендерными особенностями социального развития. Отмечается нарастание негативных признаков формирования общества риска [3].

Гендерный конфликт является социокультурным феноменом общественного развития, в котором обнаруживается конкретный способ выражения гендерных противоречий в современном мире. В связи с этим учеными ставится ряд вопросов: «1) может ли современное взаимодействие полов интерпретироваться с достаточными основаниями как социокультурный конфликт? 2) выступает ли гендерный конфликт фрактором социокультурного развития? 3) в социокультурных изменениях последних десятилетий в России обнаруживаются ли следы нарастания или, напротив, преодоления гендерного конфликта?» [4, с. 86].

В проведенных исследованиях студенческой молодежи фиксируются ценностные ориентации по ряду косвенных показателей. Студенчество находится в активной стадии вторичной социализации, которая представляет собой двусторонний процесс. Так, с одной стороны, общество постоянно в разных фрормах, разными способами и с разным эффектом задает личности ориентиры социально приемлемого поведения и мышления; с другой - происходит освоение индивидом этих организующих и ориентирующих его импульсов, идущих от общества.

Как принято считать, в студенческие годы на личность начинает оказывать все большее влияние макросоциальная среда: она понимается как источник ориентаций и регулятор выбора жизненных позиций. Следовательно, ценностные ориентации, во-первых, во многом будут отражать принятые в обществе жизненные ориентиры, во-вторых, будут зависеть от актуальной ситуации, подвергаться адаптивным изменениям. И в то же время ценностные ориентации достаточно автономны и могут передаваться от поколения к поколению не только в порядке прямого наследования, но и через сетевую коммуникацию в многообразных социальных общностях [5].

Ценностные ориентации современной молодежи России, сорормировавшиеся в период активного экономического роста и социальной трансформации общества, позволяют отметить ряд четко обозначенных тенденций, которые оказывают важное, а порой и доминирующее влияние на особенности профессионального выбора, профессиональной социализации, профессиональные ожидания молодых людей в процессе их интеграции в профессиональное сообщество.

В период с сентября по ноябрь 2018 г. был проведен очередной этап авторского общероссийского мониторинга (2004-2018), посвященный изучению ценностных ориентаций студенческой молодежи России. Исследование продолжает проводившиеся ранее (1995-2011), в том числе под руководством автора, на базе Союза негосударственных вузов Москвы и Московской области и Московского гуманитарного университета опросы студентов ряда негосударственных и государственных вузов относительно их жизненных и профессиональных планов, представлений о социальных ценностях, ценности образования и т. д.

Объектом исследования выступила студенческая молодежь России. В исследовании приняли участие студенты гуманитарного профиля 2-3-х курсов преимущественно очной формы обучения. Выборка по рассматриваемой целевой группе характеризуется как многоступенчатая, на последнем уровне гнездовая, репрезентативная, квотная в отношении критериев отбора подвыборок. Объем выборки на этапе 2018 г. составил 1748 чел.

По итогам исследования 2018 г. контингент студенческой молодежи представлен примерно равными гендерными долями. Первичная включенность студенческой молодежи, как юношей, так и девушек, определяется по базовым коммуникационным схемам, что подтверждается полученными статистическими данными, состоящими в том, что большинству студентов нравится их студенческая группа. За последние годы нельзя однозначно заявить, что среди девушек наивысшие оценки группы (10 и 9 баллов) встречаются чаще, чем среди юношей. Оценки среди девушек и юношей за последние пять лет распределились следующим образом: 51,8 и 50,0 \% в 2018 г.; 50,7 и 47,2 \% в 2017 г.; 50,2 и 52,1 \% в 2016 г.; 52,9 и 52,8 \% в 2015 г.; 52,7 и 45,1 \% в 2014 г.

Среди девушек фрактор «разочарование в избранной профессии» обозначается чаще, чем среди юношей. Пропорциональное распределение ответов на данный вопрос $\approx 2: 1$. 
Оценивая значимые ценностные качества, сначала присущие современной молодежи, затем, по их мнению, старшему поколению, и, наконец, свои собственные, девушки чаще называют нравственно-ценностные ориентиры: «доброжелательность» - 15,0 и 25,6 \% в оценках юношей и девушек соответственно (21,4 и 30,6 \% - в 2017 г.; 21,0 и 34,0 \% - 2016 г.; 21,0 и 26,8 \% 2015 г.), «ответственность» - 7,3 и 16,6 \% в ответах юношей и девушек по итогам исследования 2018 г. (14,6 и 23,4 \% - в 2017 г.; 16,1 и 21,2 \% - 2016 г.; 10,8 и 18,2 \% - 2015 г.), но в целом гендерные различия в ответах незначительны.

С небольшой долей дифференциации (42 и 46 \% соответственно) юноши и девушки отмечают, что их жизнь за последние годы изменилась к лучшему, что они нацелены на будущую работу по специальности. Вместе с тем определяя себя патриотами, примерно 2/3 опрошенных (72 \% юношей и 65 \% девушек) отвечают, что, если бы им предложили выгодный контракт, который предполагает выезд за границу на постоянное место жительства, они бы согласились.

Порядка 40 \% с небольшой долей дифференциации (40% юношей и 41 \% девушек) говорят, что при возможности повторного выбора выбрали бы вуз, в котором учатся. Примерно столько же (39 и 43 \%) склонны к обучению в традиционной форме, не желают менять форму на дистанционную или смешанную.

Свои перспективы на рынке труда студенческая молодежь в равной степени определяет как успешные для возможности занятости по получаемой профессии. Однако в отношении жизненных планов юноши в большей степени делают акцент на материальном благополучии и карьерном росте, подтверждая эти намерения стремлениями к власти, в то время как для девушек важными позициями хорошей жизни наряду с материальным благополучием и хорошей работой являются здоровье $(70 \%)$ и семья $(68 \%)$.

В целом результаты исследования позволяют сделать вывод, что разница в процентных соотношениях по ряду вопросов между юношами и девушками возможна при условии эмоционально-ценностной окраски предлагаемых позиций, необходимости включения и исполнения социально значимой роли, ориентированной на малую социальную группу. Все это лишь отчасти является непосредственным условием профессиональной ориентации. Ранее сделанный вывод о возможности оценки студенческой молодежи по принципу внутреннего единства этой группы находит подтверждение и в рамках исследования данного этапа.

В социальном поле профессиональной ориентации молодежи проблемных точек можно и не увидеть, в то время как при рассмотрении включения студенческой молодежи в систему трудовых отношений можно выявить, что ее поведение определяется не только, а зачастую и не столько профессиональной ориентацией и мотивацией, сколько базовыми ценностями.

\section{Ссылки:}

1. Lidaka A. Professional Values in Youth Education // European Scientific Journal. 2013. December. Vol. 1. P. 399-408.

2. Лапин Н.И. Проблемы фрормирования концепции и человеческих измерений стратегии поэтапной модернизации России и ее регионов // Социологические исследования. 2014. № 7. С. 8-19; Новые идеи в социологии : монография / отв. ред. Ж.Т. Тощенко. М., 2013. 479 с.

3. Зубок Ю.А. Феномен риска в социологии. Опыт исследования молодежи : монография. М., 2007. 285 с. ; Молодежь в обществе риска / В.И. Чупров, Ю.А. Зубок, К. Уильямс. 2-е изд. М., 2003. 230 с.

4. Луков Вал.А., Кириллина В.Н. Гендерный конфрликт: система понятий // Знание. Понимание. Умение. 2005. № 1. С. 86-101.

5. Ж Журавлева Н.А. Динамика ценностных ориентаций личности в российском обществе. М., 2006. 333 с. ; Ковалева А.И., Луков Вал.А., Перинская Н.А. Социология молодежи: научная школа Московского гуманитарного университета: в 2 ч. M., 2016-2018; Lukov V.A. The Conceptualization of Young People in the Twenty-First Century: New Ideas and Approaches // Russian Education and Society. 2013. Vol. 55, no. 4. April. P. 3-24. https://doi.org/10.2753/res1060-9393550401.

\section{References:}

Chuprov, VI, Zubok, YuA \& Williams, K 2003, Youth in the Risk Society, $2^{\text {nd }}$ ed., Moscow, 230 p., (in Russian). Kovaleva, Al, Lukov, ValA \& Perinskaya, NA 2016-2018, Sociology of Youth: Science School of Moscow University of Humanities, in 2 parts, Moscow, (in Russian).

Lapin, NI 2014, 'Problems of Formation of the Concept and Human Dimensions of the Strategy of Phased Modernization of Russia and Its Regions', Sotsiologicheskiye issledovaniya, no. 7, pp. 8-19, (in Russian).

Lidaka, A 2013, 'Professional Values in Youth Education', European Scientific Journal, Dec., vol. 1, pp. 399-408.

Lukov, VA 2013, 'The Conceptualization of Young People in the Twenty-First Century: New Ideas and Approaches', Russian Education and Society, vol. 55, no. 4, Apr., pp. 3-24, https://doi.org/10.2753/res1060-9393550401.

Lukov, ValA \& Kirillina, VN 2005, 'Gender Conflict: A System of Concepts', Znaniye. Ponimaniye. Umeniye, no. 1, pp. 86101, (in Russian).

Toshchenko, ZhT (ed.) 2013, New Ideas in Sociology: a monograph, Moscow, 479 p., (in Russian).

Zhuravleva, NA 2006, Dynamics of Value Orientations of the Individual in Russian Society, Moscow, 333 p., (in Russian).

Zubok, YuA 2007, The Phenomenon of Risk in Sociology. Experience of Youth Research: a monograph, Moscow, 285 p., (in Russian). 